\title{
AN UPDATE ON ALCOHOLIC STEATOHEPATITIS
}

\author{
Bickram Pradhan ${ }^{1}$, Lubina Arjyal ${ }^{2}$, Shatdal Chaudhary ${ }^{3}$.
}

\begin{abstract}
Alcoholic steato hepatitis (ASH) is an acute hepatic manifestation occurring from heavy alcohol ingestion. It is associated with liver failure, hepatorenal syndrome, severe sepsis and increased mortality. Patients with severe ASH have reported short-term mortality of up to $40 \%-50 \%$. Although approximately $20 \%$ of alcoholics undergoing liver biopsy reveal histological features of alcoholic hepatites $(\mathrm{AH})$ only a minority progress to severe alcoholic hepatitis (AH) with markedly elevated serum liver enzymes, jaundice and impaired liver function. Prognostic scores include the Maddrey's discriminant function, the model of end-stage liver disease, the Glasgow Alcoholic Hepatitis score, and the ABIC score. The response to corticosteroid therapy can be assessed using the Lille model. Severe ASH at risk of early death should be identified by one of the available prognostic scoring systems before considering specific therapies. Corticosteroids are the mainstay of treatment for severe ASH. When corticosteroids are contraindicated, Pentoxifylline may be alternatively used. This review article aims to discuss theclinical features, diagnosis, prognostic models, and treatment of ASH.
\end{abstract}

KEYWORDS: Alcoholic steatohepatitis; ABIC score; Alcoholic hepatitis

1. Professor and In charge, Division of Gastroenterology and Hepatology, Department of Internal medicine, B P Koirala Institute of Health Sciences, Dharan, Nepal

2. Research Officer, B P Koirala Institute of Health Sciences, Dharan, Nepal

3. Associate Professor, Department of Internal Medicine, Universal College of Medical Sciences \&Teaching Hospital, Bhairahawa, Nepal

\author{
For Correspondence \\ Dr. Bickram Pradhan, MD \\ Professor of Internal Medicine, \\ In charge, Division of Gastroenterology and Hepatology \\ Department of Internal Medicine, \\ B P Koirala Institute of Health Sciences, Dharan, Nepal \\ E-mail: bickram.p@gmail.com
}




\section{INTRODUCTION}

The clinical syndrome of jaundice or abnormal liver function tests in alcohol abusers is called alcoholic hepatitis. Though historically referred to as acute alcoholic hepatitis, this is probably a misnomer as alcoholic hepatitis is usually associated with extensive liver fibrosis and cirrhosis and often follows a protracted course, weeks after alcohol abstinence. Alcoholic steatohepatitis (ASH) is the leading cause of decompensation of alcoholic cirrhosis in non-abstinent patients. ASH is histologically characterized by coexistent steatosis, hepatocyte ballooning and polymorphonuclear cell infiltrates.In particular, the short-term mortality in patients with severe ASH has been extremely high up to $40 \%-50 \% .1$, 2Although several therapeutic measures are now available to improve survival in those with severe alcoholic hepatitis (AH), overall prognosis remains gloomy.

$\mathrm{ASH}$ is not exclusively accompanied by $\mathrm{AH}$ but can be superimposed on any different stages of ALD comprising steatosis, steatohepatitis, fibrosis, and cirrhosis.3, 4In addition, the true incidence and prevalence of $\mathrm{ASH}$ or $\mathrm{AH}$ among alcohol abusers remain unclear due to the uncertainties behind a clinical diagnosis of $\mathrm{AH}$ and the limited number of studies with liver biopsy to ascertain a histologic diagnosis of ASH.

\section{HISTOLOGY OFASH}

A coexistence of hepatocyte ballooning, steatosis and an inflammatory infiltration with PMN are seen in ASH as well as in NASH. The presence of Mallory Hyaline bodies and mega mitochondria are also found in both conditions. At standard histological examination no single criteria can differentiate ASH from NASH (so initially called pseudo alcoholic hepatitis). However the lesions are more pronounced in ASH as compared to NASH. In addition presence of these lesions with a history of active drinking suggests ASH.

\section{CLINICAL MANIFESTATION AND EVALUATION}

Symptomatic ASH usually present with progressive jaundice. However it should be a differential in any patients with alcohol abuse presenting with decompensation such as ascites, hepatic encephalopathy and gastrointestinal bleeding. Palmarerythema, spider naevi and gynecomastia are especially prevalent when alcohol is the cause of steatohepatitis. Malnutrition, weight loss and muscle wasting are also commonly associated. Malnutrition is due to promiscuous eating habits, alcohol related diarrhoea, decreased small bowel absorption capacity, anorexia, and an excessive catabolic state, which is directly related to increased mortality.5An enlarged liver is often present which may be tender. ASH is often associated with SIRS with or without infections. Despite the wide range of severity at presentation, those with severe ASH (Maddrey's discriminant function? 32) typically present with fever, jaundice and abdominal tenderness. Severe ASH may progress to multi-organ failure including acute kidney injury and infection. Thus, infection and renal failure have a major impact on survival and should be closely monitored in patients with severe ASH. Severe ASH at risk of early death should be identified by one of the available prognostic scoring systems before considering specific therapies.

Serum AST levels, which may be normal in asymptomatic forms are typically elevated to 1-6 times the upper limit of normal range, the AST/ALT ratio is usually greater than 2 . Low serum albumin, prolonged prothrombin time and elevated International normalized ratio (INR) reflect the severity of liver dysfunction. Neutrophilia, sometimes of high level is a frequent feature of ASH, besides the possibility of leucopenia asseen in cirrhosis.

Imaging studies of liver, in addition to detecting signs of liver disease, may show evidence of liver "arterialization" which is related to increased resistance to portal venous blood flow and the resulting dilatation of hepatic artery. The hepatic venous pressure gradient, measured during transvenous liver biopsy is an accurate reflection of portal pressure in ASH and has prognostic significance. Sharp portal pressure increase reflects the severity of ASH. Healing process can be accompanied by marked decrease in portal pressure.

\section{PROGNOSTIC SCORING SYSTEMS}

Different prognostic scores have been developed primarily to select patients with severe ASH at high risk of early $(1,2$, or 3 months) death. 6-10 There are several disease-specific prognostic models (MDF: Maddrey's Discriminant Function;GAHS: Glasgow Alcoholic Hepatitis Score; ABIC: Age-Bilirubin-INR-Creatinine Score; Lille model; MAGIC: Model for Alcoholic hepatitis to Grade the severity In an Asian patient Cohort,) and a non-disease-specific model (MELD: Model for End-Stage Liver Disease).6-10

\section{Maddrey's Discriminant Function(MDF)}

$\mathrm{MDF}=$ bilirubin $(\mathrm{mg} / \mathrm{dl})+4.6 \mathrm{x}$ (patient $\mathrm{PT}-$ control PT). MDF was developed in 1978 and is still the most common scoring system to stratify patients into severe and non-severe ASH with scores? 32 as cut off point.10Severe ASH (MDF? 32) mostly progress to the systemic inflammatory response syndrome (SIRS) and multi-organ failure. In the absence of 
treatment, the one month spontaneous survival of patients with DF ? 32 is $50-65 \%$ but it is limited by difficulties in standardizing prothrombintime, presence of only two categories, severe and non- severe and lack of dynamic information to assess response to treatment.

\section{MAGIC}

MAGIC is a recently developed, new model to predict liverrelated death in Asian patients hospitalized for AH. It mainly focuses on the prediction of natural outcomes of untreated patients with $\mathrm{AH}$ and firstly brought the prognostic role of hyperkalemia in AH to light. However, this model needs s further validation in other ethnic populations with severe $\mathrm{ASH}$

\section{Glasgow Alcoholic Hepatitis Score (GAHS)}

Table 1: THE GAHS

\begin{tabular}{|lllr|}
\hline & \multicolumn{3}{c|}{ Score given } \\
\hline & 1 & 2 & 3 \\
\hline Age & $<50$ & $\geq 50$ & - \\
\hline WBC $(109 / 1)$ & $<15$ & $\geq 15$ & - \\
\hline Urea $(\mathrm{mmol} / \mathrm{l})$ & $<5$ & $\geq 5$ & - \\
\hline PT ratio or INR & $<1.5$ & $1.5-2.0$ & $>2.0$ \\
\hline Bilirubin $(\mu \mathrm{mol} / \mathrm{l})$ & $<125$ & $125-250$ & $>250$ \\
\hline
\end{tabular}

It is based on 5 laboratory values and can be calculated at day 1 or days 6-9 to provide dynamic information. In patients with MDF? 32 and GAHS ? 9, the 28 days survival was 52\% in untreated patients and $78 \%$ if treated with corticosteroids. In patients with scores ? 9, there was no difference in survival between treated and untreated groups. 11

\section{MELD score}

The Model for End-Stage Liver Disease (MELD) was originally developed to assist the allocation of liver grafts to patients on the transplant waiting list, but has also been used to direct the decision for corticosteroid therapy in patients with AH. Parameters used in calculating the MELD score include serum bilirubin levels, INR, and serum creatinine, and openly accessible calculators (http://www.unos.org/ resources/ meldpeldcalculator.asp?index $=98$ ) render its application simple and fast. Moreover, clinical studies comparing DF vs. MELD have shown an equally good predictive value of bothscores indicating a poor prognosis in $\mathrm{AH}$. 7,12

\footnotetext{
ABIC score

Using the variables available at admission (Age, serum Bilirubin, INR and serum Creatinine), ABIC score was
}

generated. The resulting score was: $[($ age $\times 0.1)+($ serum bilirubin $\times 0.08)+($ serum creatinine $\times 0.3)+(\operatorname{INR} \times 0.8)]$. The values obtained ranged from 4.9 to 12.26 . Using a cutoff value of 6.71 and 9.0 (optimal cut points with better sensitivity and specificity), this score identified patients with $\mathrm{AH}$ that have low, intermediate, and high risk of death at 90 days. 6

\section{Lille Score}

While the previous scores all aimed to assist the prediction of mortality, the Lille Model has been created to assess a patient's response to corticosteroids, and to decide whether corticosteroids should be stopped in those not responding to 7 days of prednisolone $40 \mathrm{mg}$ /day. 13 The score combines age, renal insufficiency, albumin, prothrombin time, bilirubin, and evolution of bilirubin at day 7 which, taken together, are highly predictive of death at 6 months of follow-up. The Lillemodel has been validated and replicated repeatedly, and allows for stratifying patients into responders, partial responders and non-responders (Table 2). Separating corticosteroid "responders" from "non-responders" is important to avoid ineffective corticosteroid therapy in patients who are often charged with concomitant infections and to consider other therapeutic options.

\section{Table 2. The Lille model}

Lille score $=3.19-0.101 \times($ age $[$ years] $)+0.147 \times($ albumin day $0[\mathrm{~g} / \mathrm{L}])+0.0165 \times($ Bilirubin day $1[\mathrm{~mol} / \mathrm{L}]-$ Bilirubin day $7[\mathrm{~mol} / \mathrm{L}])-(0.206 \times$ presence of kidney failure $\mathrm{y} / \mathrm{n})$ $0.0065 \times($ Bilirubin day $0[\mathrm{~mol} / \mathrm{L}])-0.0096 \times \mathrm{INR}$

Allows stratification of patients with $\mathrm{AH}$ according to response tocorticosteroid therapy: complete responders (Lille score ? 0.16), partialresponders (Lille score 0.16-0.56) and null responders (Lille? 0.56)

\section{TREATMENT}

\section{General measures in treatment of all forms of ASH}

\section{Alcohol Abstinence}

Complete abstinence is the therapeutic backbone in patients with $\mathrm{AH}$, but even in those who manage to stop drinking, $\mathrm{AH}$ may persist and progress towards liver failure. Baclofen could effectively suppress a craving for alcohol.

Withdrawal symptoms Patients developing severe withdrawal symptoms or delirium tremens can be treated with both shortacting benzodiazepines but the risk of worsening encephalopathy should be kept in mind. 


\section{Malnutrition}

Patients with AH often suffer from serious malnutrition. Thus, counterbalancing nutritional deficiencies may theoretically improve the prognosis of patients with $\mathrm{AH}$. Intravenous thiamine should be administered. A daily protein intake of $1.5 \mathrm{~g} / \mathrm{Kg}$ of body weight should be ensured, irrespective of the presence of encephalopathy. TEN by oral nutritional supplements in patients with $\mathrm{AH}$ is recommended by the European Society for Parenteral and Enteral Nutrition (ESPEN) since it improves nutritional status and survival in severely malnourished patients with AH.14

\section{Renal function}

Renal dysfunction is frequent during the course of severe ASH and represents an important predictor of infection and survival. The most common cause of acute renal dysfunction is HRS. To prevent HRS, nephrotoxic drugs such as nonsteroidal anti-inflammatory drugs, aminoglycoside, diuretics and contrast dye should be avoidedand volume expanders including albumin and fresh frozenplasma might be administered.

\section{Infections}

Bacterial infectionis frequent but difficult to diagnose, since SIRS criteriaare often associated with sterile inflammation in ASH. Infection is commonly seen in around $25 \%$ of patientswith severe ASH at admission and another quarter finallybecome infected while receiving corticosteroids duringadmission. Infection screening should be systematic at admission and at regular intervals. Empirical use of antibiotics, although widely used is not warranted.

\section{Specific measures in severe ASH}

\section{Steroids}

A meta-analysis of individual patient data from the most recent placebo controlled studies with an adequate number of patients and appropriate quality demonstrated that 28-day survival was significantly higher in corticosteroid-treated patients than in non-corticosteroid treated patients $(80 \mathrm{vs}$ $66 \%$ ). These trials only included patients with severe $\mathrm{AH}$ as defined by DF ?32 or encephalopathy, and the survival benefit derived from corticosteroids waspred ominantly observed in patients classified as responder's orpartial responders by the Lille model confirming the predictive role of this composite score. 15
Prednisolone at 40mg per day for 28 days and then stopped or tapered down over 2 weeks are suggested. The full course however, shouldonly be administered in patients who show an adequateresponse to corticosteroids, whereas patients with a Lille score above 0.45 after 7 days of corticosteroids are unlikely torespond, and more likely to develop corticosteroidassociated adverse effects. The interruption of corticosteroidsis particularly recommended in those identified as nonrespondersas per a Lille score of $>0.56$. However the following limitations of the use of corticosteroid are also delineated

1. Efficacy of steroids only demonstrated in biopsy proven $\mathrm{ASH}$ and may be harmful in conditions other than ASH which represent $10-30 \%$ of patients with a clinical diagnosis of AH.

2. Steroids should not be used in the treatment of non-severe ASH.

3. About $60 \%$ of patients with severe ASH benefits from corticosteroids. Thus early identification of non responders is important to stop and limit the exposure to steroids.

4. Infection is a contraindication for corticosteroids use. However it can be used after infection is controlled.

\section{Pentoxifylline}

Pentoxifylline is an antioxidant and a weak anti-TNF agent.In patient with severe ASH receiving Pentoxifylline, a 6-month survival rate was higher thanin those treated with placebo.16The survival benefit wasattributable to a lower incidence of HRS.However, thisbeneficial effect was challenged by two recent meta-analysesdemonstrating that pentoxifylline decreased the risk of fatal HRS but did not improve survival significantly, although it remains inconclusive. 17, 18 However in patients with severe ASH and uncontrolled sepsis, it can be considerd as a first line of therapy.

\section{Anti TNF? agents}

TNF? is considered a major trigger of alcohol-associated necro-inflammation and thus, its neutralization with TNF? antibodies is an attractive therapeutic concept. The most potent anti-TNF substances in this regard are infliximab and etanercept which both have been tested in AH. However the effectiveness of these agents was not confirmed in clinical trials. 19,20

\section{$\mathrm{N}$-acetyl cysteine (NAC)}


The use of NAC in patients with severe $\mathrm{AH}$ is based on the concept that consumption of large amounts of alcohol causes oxidative stress and depletion of glutathione. Recently, the combination treatment with NAC and prednisolone significantly reduced a 1-month mortality rate compared with prednisolone alone by preventing HRS and infection, although the difference was no longer statistically significant at 3 and 6 months. 21

\section{Liver transplantation}

$\mathrm{AH}$ is not considered as a usual indication for liver transplantation (LT).In many countries, patients with decompensated ALDare only listed for liver transplantation provided they cansubstantiate a 6 -months period of abstinence. Recently, an early LT concept was suggested to those with a first episode of severe ASH not responding to steroids. Explicit improvement of survival was observed in patients who received early LT compared to historical controls without response to steroids.22Obviously, early LT in ASH may be relevant only in highly selected patients with a first episode of severe ASH, a favorable addiction profile, and not responding to medical therapy.

\section{REFERENCES}

1. Lucey MR, Mathurin P, Morgan TR. Alcoholic hepatitis. NEnglJ Med 2009; 360: 275869

http://dx.doi.org/10.1056/NEJMra0805786 PMid:19553649

2. Mathurin P, Duchatelle V, Ramond MJ, Degott C, Bedossa P, Erlinger S, Benhamou JP, Chaput JC, Rueff B, Poynard T. Survival and prognostic factors in patients with severe alcoholic hepatitis treated with prednisolone. Gastroenterology1996; 110: 1847-53.http://dx.doi.org/10.1053/gast.1996.v110.pm8964410 PMid:8964410

3. Dhanda AD, Collins PL, McCune CA. Is liver biopsy necessary in the management of alcoholic hepatitis? World $J$ Gastroenterol2013; 19: 7825-29.

http://dx.doi.org/10.3748/wjg.v19.i44.7825 PMid:24307775 PMCid:PMC3848129

4. Sougioultzis S, Dalakas E, Hayes PC, Plevris JN. Alcoholic hepatitis: from pathogenesis to treatment. Curr Med Res Opin2005; $21: 1337-46$

http://dx.doi.org/10.1185/030079905X56493 PMid:16197651

5. Mendenhall CL, Moritz TE, Roselle GA, Morgan TR, Nemchausky BA, Tamburro CH, Schiff ER, McClain CJ, Marsano LS, Allen JI. Protein energy malnutrition in severe alcoholic hepatitis: diagnosis and response to treatment. The VA Cooperative Study Group \#275. JPEN J Parenter Enteral Nutr1995; 19: 258-65 http://dx.doi.org/10.1177/0148607195019004258 PMid:8523623

6. Dominguez M, Rincón D, Abraldes JG, Miquel R, Colmenero J, Bellot P, García-Pagán JC, Fernández R, Moreno M, Ba-ares $R$, Arroyo V, Caballería J, Ginès P, Bataller R. A new scoring system for prognostic stratification of patients with alcoholic hepatitis. Am J Gastroenterol 2008; 103: 2747-56. http://dx.doi.org/10.1111/j.1572-0241.2008.02104.x PMid:18721242

7. Dunn W, Jamil LH, Brown LS, Wiesner RH, Kim WR, Menon KV, Malinchoc M, Kamath PS, Shah V. MELD accurately predicts mortality in patients with alcoholic hepatitis. Hepatology2005, 41: 353-8.http://dx.doi.org/10.1002/hep.20503 PMid:15660383

8. Forrest EH, Evans CD, Stewart S, Phillips M, Oo YH, McAvoy NC, Fisher NC, Singhal S, Brind A, Haydon G, O'Grady J, Day CP, Hayes PC, Murray LS, Morris AJ. Analysis of factors predictive of mortality in alcoholic hepatitis and derivation and validation of the Glasgow alcoholic hepatitis score. Gut 2005, 54: 1174-79.http://dx.doi.org/10.1136/gut.2004.050781 PMid:16009691 PMCid:PMC1774903

9. Lee M, Kim W, Choi Y, Kim S, Kim D, Yu SJ, Lee JH, Kim HY, Jung YJ, Kim BG, Kim YJ, Yoon JH, Lee KL, Lee HS. Spontaneous evolution in bilirubin levels predicts liver related mortality in patients with alcoholic hepatitis. PLoS One 2014; 9: e100870. [PMID: 25013906 DOI: 10.1371/journal.pone.0100870] http://dx.doi.org/10.1371/journal.pone.0100870

10. Maddrey WC, BoitnottJK, Bedine MS, Weber FL, Mezey E, White RI.Corticosteroid therapy of alcoholic hepatitis. Gastroenterology 1978; 75: 193-9. PMid:352788

11. Forrest EH, E.C, Stewart S, Philips M etal. Analysis of factors predictive of mortality in alcoholic hepatitis and derivation and validation of the Glasgow Alcoholic Hepatitis Score. Gut .2005, 54(8):p 2747-56.http://dx.doi.org/10.1136/gut.2004.050781 PMid:16009691 PMCid:PMC1774903

12. Srikureja W, Kyulo NL, Runyon BA, Hu KQ. MELD score is a better prognostic model than Child-Turcotte-Pugh score or Discriminant Function score in patients with alcoholic hepatitis. JHepatol 2005;42:700-6. http://dx.doi.org/10.1016/j.jhep.2004.12.022 PMid:15826720

13. Louvet A, Naveau S, Abdelnour M, et al. e Lille model: a new tool for therapeutic strategy in patients with severe alcoholic hepatitis treated with steroids. Hepatology 2007;45:1348-54. http://dx.doi.org/10.1002/hep.21607 PMid:17518367

14. Plauth M, Cabré E, Riggio O, et al. ESPEN Guidelines on Enteral Nutrition: Liver disease. ClinNutr 2006;25:285-94. http://dx.doi.org/10.1016/j.clnu.2006.01.018 PMid:16707194 
15. Mathurin P, O'Grady J, Carithers RL, et al. Corticosteroids improve short-term survival in patients with severe alcoholic hepatitis: metaanalysis of individual patient data. Gut 2011;60:255-60. http://dx.doi.org/10.1136/gut.2010.224097 PMid:20940288

16. Akriviadis E, Botla $R$, Briggs $W$, Han $S$, Reynolds $T$, ShakilO.Pentoxifylline improves short-term survival in severe acutealcoholic hepatitis: a double-blind, placebo-controlled trial.Gastroenterology 2000; 119: 1637-48. http://dx.doi.org/10.1053/gast.2000.20189 PMid:11113085

17. Parker R, Armstrong MJ, Corbett C, Rowe IA,HoulihanDD. Systematic review: pentoxifylline for the treatment of severealcoholic hepatitis. Aliment PharmacolTher2013; 37: 845-54.http://dx.doi.org/10.1111/apt.12279 PMid:23489011

18. Whitfield K, Rambaldi A, Wetterslev J, Gluud C. Pentoxifyllinefor alcoholic hepatitis. Cochrane Database Syst Rev 2009;(4): CD007339 PMid:19821406

19. Emille D. A double blind randomized controlled trial of infliximab associated with prednisolone in acute alcoholic hepatitis. Hepatology, 2004, 39:13907.

http://dx.doi.org/10.1002/hep.20206

PMid:15122768
20. Boetticher NC, P.C, Kwo P, Abrams GA et al. a randomized double blind placebo-controlled multicenter trial of etanercept in the treatment of alcoholic hepatitis. Gastroenterology, 2008. 135(6): 1953-60.http://dx.doi.org/10.1053/j.gastro.2008.08.057 PMid:18848937 PMCid:PMC2639749

21. Nguyen-Khac E, Thevenot T, Piquet MA, Benferhat $S$, Goria $O$, Chatelain D, Tramier B, Dewaele F, Ghrib $S$, Rudler M, Carbonell N, Tossou H, Bental A, Bernard-Chabert B, Dupas JL. Glucocorticoids plus $\mathrm{N}$-acetylcysteine in severe alcoholic hepatitis.NEngl JMed 2011; 365: 1781-9. http://dx.doi.org/10.1056/NEJMoa1101214 PMid:22070475

22. Mathurin P, Moreno C, Samuel D, Dumortier J, Salleron J, Durand F, Castel H, Duhamel A, Pageaux GP, Leroy V, Dharancy $S$, Louvet A, Boleslawski E, Lucidi V, Gustot T, Francoz C, Letoublon C, Castaing D, Belghiti J, Donckier V, Pruvot FR, Duclos-Vallée JC. Early liver transplantation for severe alcoholic hepatitis.NEngl J Med 2011; 365: 1790 1800.http://dx.doi.org/10.1056/NEJMoa1105703 PMid:22070476 